\title{
The Impact of Language Barriers Faced by Counsellors and Refugee Clients in Counselling: A Systematic Review
}

Kimberly Tiong Khoong Ling, Siti Aishah Hassan, Othman Jailani

To Link this Article: http://dx.doi.org/10.6007/IJARBSS/v11-i12/11904

DOI:10.6007/IJARBSS/v11-i12/11904

Received: 09 October 2021, Revised: 14 November 2021, Accepted: 28 November 2021

Published Online: 21 December 2021

In-Text Citation: (Ling et al., 2021)

To Cite this Article: Ling, K. T. K., Hassan, S. A., \& Jailani, O. (2021). The Impact of Language Barriers Faced by Counsellors and Refugee Clients in Counselling: A Systematic Review. International Journal of Academic Research in Business and Social Sciences, 11(12), 1771-1787.

\section{Copyright: @ 2021 The Author(s)}

Published by Human Resource Management Academic Research Society (www.hrmars.com)

This article is published under the Creative Commons Attribution (CC BY 4.0) license. Anyone may reproduce, distribute, translate and create derivative works of this article (for both commercial and non0-commercial purposes), subject to full attribution to the original publication and authors. The full terms of this license may be seen at: http://creativecommons.org/licences/by/4.0/legalcode

Vol. 11, No. 12, 2021, Pg. 1771 - 1787

Full Terms \& Conditions of access and use can be found at http://hrmars.com/index.php/pages/detail/publication-ethics 


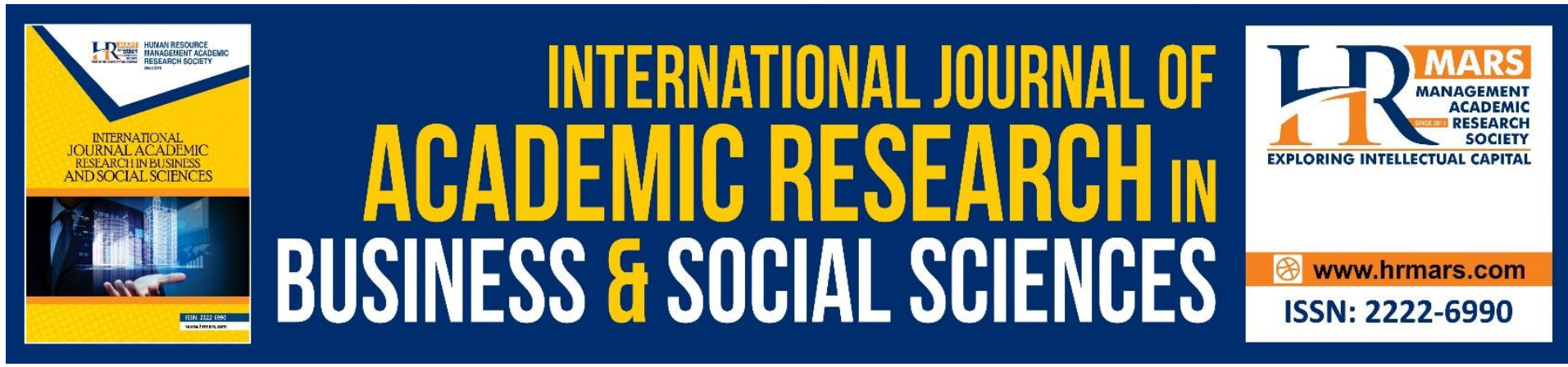

\title{
The Impact of Language Barriers Faced by Counsellors and Refugee Clients in Counselling: A Systematic Review
}

\author{
Kimberly Tiong Khoong Ling, Siti Aishah Hassan, Othman \\ Jailani
}

Department of Counselor Education and Counseling Psychology, Faculty of Educational Studies, Universiti Putra Malaysia, 43400 UPM Serdang, Selangor, Malaysia

Email: obj@upm.edu.my

\begin{abstract}
Language is one of the most essential means to communicate with each other during counselling. However, refugee clients often come from different cultural backgrounds, which will lead to them having varying languages. This will create a language barrier between counsellors and clients. Due to this reason, many counsellors faced numerous challenges to working with clients and the same could be said otherwise. This systematic review aims to explore and discover the impact of language barriers faced by counsellors and refugee clients in counselling. The impacts analyzed in this paper revealed a lack of readiness from both sides, changes in emotional aspect, difficulty understanding each other and the need to rely on interpreters to act as the intermediaries. Therefore, workshops and trainings should be applied to better prepare the counsellors to work in these settings and awareness of these counselling services with interpreters among refugees.
\end{abstract}

Keywords: Language, Linguistic, Barriers, Counsellors, Refugee, Clients

\section{Introduction}

According to the United Nations High Commissioner for Refugees [UNHCR] (2020), there were around 79.5 million people worldwide being forcibly displaced. These people were being displaced due to war, conflict, insecurity, religion, ethnicity, political persecution, human rights violations and gender identity prosecutions. In order to survive, they would need to move to other countries to gain stability. These people were called refugees and asylum seekers.

However, moving into another country is not easy. Beiser and Hou (2017) mentioned that refugees would often have lower mental health compared to other migrants as they faced more barriers and challenges than the general population (Aspinall \& Watters, 2010; Blackmore et al., 2020). The challenges would include discrimination (Shaw et al., 2020; Ziersch et al., 2020), loneliness, lack of support from loved ones (Crepet et al., 2017; Frounfelker et al., 2020) and lack of opportunities and control (Sagbakken et al., 2020).

Due to these reasons, Eaton et al (2011) stated that compared to the general population, asylum seekers are 5 times more likely to develop mental health problems and 
$61 \%$ of asylum seekers would experience severe mental distress. According to Blackmore et al. (2020), the number of refugees experiencing mental health problems would keep on rising even years after they were displaced. The most common mental health problems faced by refugees may include depression and PTSD, while anxiety disorders and psychosis were more common in refugees than in the general population (Blackmore et al., 2020). These challenges may significantly impact their lives and they would often be in need of counselling (Silove et al., 2017). However, most of the time, counsellors working with clients that have an unrevealed cultural past may create new challenges (Jefee-Bahloul et al., 2014 as cited in Schelechter et al., 2020). According to Salami et al (2019), language barriers were one of the more well-known barriers for people accessing mental health care services.

The definition of language is an order of standard spoken, manual, or written symbols that are used by groups of people to express themselves and communicate (Robins et al., 2021). However, as refugees came from other countries, most of them speak different languages from one another. This makes it difficult for counsellors to work with them as they do not understand what the refugees are saying. This is known as language barriers.

Other than that, many refugee clients also had their own challenges due to their cultural backgrounds and religious brought-up. According to van der Boor and White (2019), most refugee families distrust the local health services, which may lead them to not reach out to counsellors. Many of them also found it hard to find someone who can speak their language and it would be a hassle for them to understand the routes to access health care needs (Boor $\&$ White, 2019). The beliefs and values that the refugee families believed in would also cause some problems. Some refugees believed that one should stay away from doctors to stay healthy (Boor \& White, 2019) and were told to trust in their religion more.

As a result of these language barriers, an alternative option may be to ask for support from an interpreter. Even so, it comes with its own challenges and opportunities. Most counsellors expressed concerns that using an interpreter would influence the quality of counselling (Hanft-Rober et al., 2018 as cited in Schlecter et al., 2020). Clients on the other hand would worry about confidentiality issues (Salami et al., 2019). Nevertheless, others may appreciate the need for interpreters and be more comfortable in the therapeutic relationship (Hadziabdic et al., 2014 as cited in Schlechter et al., 2020).

The research gap in this systematic review would be that there were limited journal articles about language barriers between counsellors and refugee clients that made it hard to understand the current situation. There were also a few numbers of research focused on the use of interpreters in counselling.

\section{Objectives}

Therefore, the purpose of this systematic review was to synthesize and compile the journal articles researching the impact of language barriers faced by counsellors and refugee clients in counselling. While our outcome variable may emphasize focus on counsellors and refugee clients, we will also include those with the use of interpreters and how it may affect the counselling session and relationship.

\section{Method}

For our review, the protocol of PRISMA guidelines (Moher, 2009) was followed closely. This review methodology involved four steps - identification, screening, eligibility and inclusion. In the step of identification, two electronic databases were used to conduct literature searches, and a variety of keywords were used separately and in combination to identify 
articles (see Figure 1). By using these guidelines, the quality of the systematic review was enhanced due to it being more organized and systematic. This systematic review initiated the idea of discovering the language barriers and challenges faced by both counsellors and refugees. Therefore, the keywords derived from this area of interest include language, counsellors and refugees. By using the advanced search in the e-database, we successfully retrieved suitable journal articles for this review and tried to minimize bias to produce a wellproduced neutral reviewed study.

\section{The Search Strategy}

The systematic review used one of the more prominent databases of information called Scopus. Another database was called ScienceDirect. Due to them being subscribed to the databases provided by Universiti Putra Malaysia (UPM) library website, they were easily accessed and used by the reviewer. The search was conducted on 6th May 2021 for Scopus and 9th May 2021 for ScienceDirect. The objective of this was to select, search and review available journal articles from different sources.

For Scopus, the search terms used in the database were "((language OR linguistic) AND (counsellor* OR refugee* OR (asylum AND seeker*)))". The search terms were only searched in the title, abstract and keywords of the literature. The total number of findings were 3578 . The filters applied for Scopus were limited from 2011 till 2021, open access, article type document, using English language. Last but not least, it was narrowed down to the subject of social sciences, arts and humanities as well as psychology. The remaining number of journal articles retained were 359 . The main reason for these filters was to focus on language and to understand how the language barriers will impact the counsellors and refugee clients.

Another subscribed database by the UPM website was used. For ScienceDirect, the search terms used were "(language OR linguistic) AND (counsellor OR refugee OR (asylum seeker)". The search terms were only applied to the title, abstract and keywords of the literature. A total of 315 pieces of literature were found. Filters were applied which included finding journal articles from 2011 till 2021, open access, and being in the subject area of social sciences, psychology, arts and humanities. Thus, 14 journal articles were left.

\section{Eligibility Criteria}

All the same eligibility criteria were applied to both Scopus and ScienceDirect. The search terms of language, linguistic, counsellor, refugee and asylum seeker were focused on the title, abstract and keywords of the literature only. Eligible studies were included if: 1) the study was a journal article or primary research paper; 2 ) the studies were conducted from 20112021 (within 10 years); 3) had the keywords of counsellor or clients and language; 4) the studies talked about the impact of language barriers faced in counselling. The exclusion criteria would include: 1 ) the study was a journal article or primary research paper (e.g. books, conference papers, editorial); 2) the study did not explore the impact of language barriers in counselling.

\section{Study Selection}

A reviewer was in charge of the screening and study selection process. The study selection process has 3 stages. First of all, a preliminary screening was conducted to identify and remove any unrelated results. These may include medical articles, conference papers, and 
pre-2010 publications. After that, a total of 373 journal articles from both Scopus and ScienceDirect were extracted into an Excel file for further analysis. 6 Additional records were identified through reference chaining. No duplicates were found. Therefore, the remaining number of journals remained the same. 379 journal articles' titles were screened. 332 journal articles were removed as they were not related to the topic, such as the word "aphasia" and in different subject areas such as in education settings. 50 journal articles were eligible for getting their abstracts screened. A total of 36 journal articles were excluded due to reasons such as using e-counselling and expressive arts. Then, 18 full-texts of the journal articles were downloaded and read through. All in all, 15 journal articles were selected for this systematic review. After the full-text screening, the reviewer selected those that best suited this systematic review, and wrote the key information in Figure 1.

\section{Figure 1}

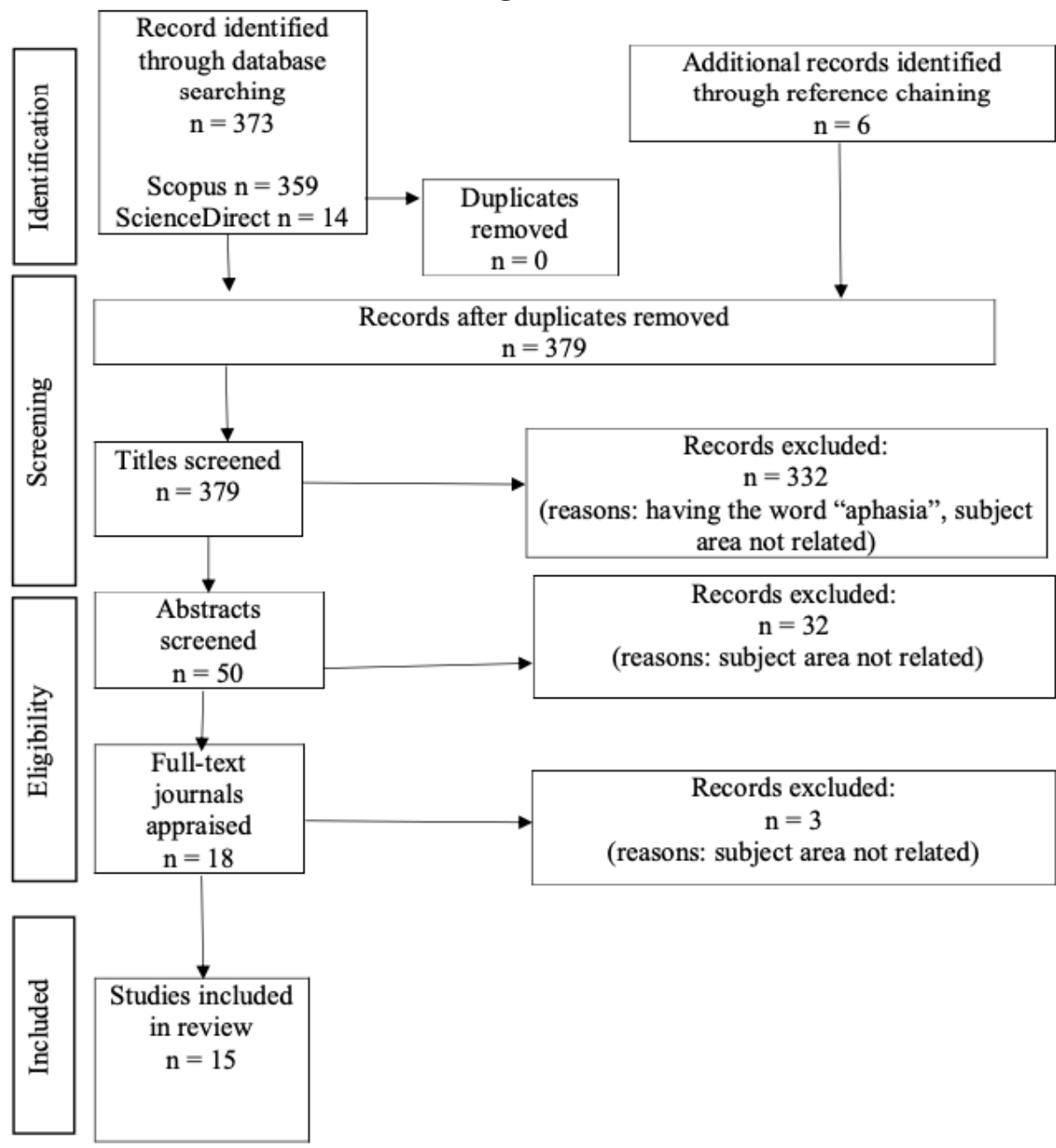

A flow diagram for selection review of studies on language barriers that counsellors and refugee clients faced in counselling.

\section{Findings of Literature Review}

Table 1 showed the process and summary of the journal articles selected. All journal articles were reviewed, extracted and organized into the author's name (year), the title of the journal, sample size and relevant findings. This table can help us to better understand the findings of each journal article. 
Table 1

Summary of Selected Literatures

\begin{tabular}{|c|c|c|c|}
\hline Author (Year) & Title & Sample Size & Relevant Findings \\
\hline $\begin{array}{l}\text { Jep Rip, Elianne } \\
\text { Zijlstra, Wendy Post, } \\
\text { Margrite Kalverboer } \\
\text { \& Erik J.Knorth (2020) }\end{array}$ & $\begin{array}{l}\text { "It can never be as } \\
\text { perfect as home": An } \\
\text { Explorative Study into } \\
\text { the Fostering } \\
\text { Experiences of } \\
\text { Unaccompanied } \\
\text { Refugee Children, } \\
\text { Their Foster Carers } \\
\text { and Social Workers }\end{array}$ & $\begin{array}{l}10 \text { refugee children, } 5 \\
\text { foster carers and } 5 \\
\text { social workers were } \\
\text { included. }\end{array}$ & $\begin{array}{l}\text { Due to language } \\
\text { barriers, it can be hard } \\
\text { to create kinship and } \\
\text { thus take a longer time } \\
\text { for social workers to be } \\
\text { informed about the } \\
\text { problems. }\end{array}$ \\
\hline $\begin{array}{l}\text { Pascal Schlechter, } \\
\text { Jens H. Hellmann, Pia } \\
\text { Wingbermühle \& } \\
\text { Nexhmedin Morina } \\
\text { (2020) }\end{array}$ & $\begin{array}{l}\text { Which Psychological } \\
\text { Characteristics } \\
\text { Influence Therapists' } \\
\text { Readiness to Work } \\
\text { with Refugees? }\end{array}$ & $\begin{array}{l}111 \quad \text { German } \\
\text { psychotherapists } \\
\text { between the ages of } \\
24 \text { till } 67 .\end{array}$ & $\begin{array}{l}\text { Language barriers can } \\
\text { negatively affect the } \\
\text { comfortability of } \\
\text { working with refugees } \\
\text { and interpreters. } \\
\text { Openness with } \\
\text { interpreters and former } \\
\text { experiences can } \\
\text { increase the readiness } \\
\text { to work with } \\
\text { interpreters. }\end{array}$ \\
\hline $\begin{array}{l}\text { Bukola Salami, } \\
\text { Jordana Salma \& } \\
\text { Kathleen Hegadoren } \\
\text { (2019) }\end{array}$ & \begin{tabular}{lr}
\multicolumn{2}{l}{ Access and Utilization } \\
of Mental & Health \\
Services & for \\
Immigrants & and \\
Refugees: & \\
Perspectives & of \\
Immigrant & Service \\
Providers &
\end{tabular} & $\begin{array}{l}53 \text { participants } \\
\text { recruited. }\end{array}$ & $\begin{array}{l}\text { Challenges for having } \\
\text { interpreters may } \\
\text { include minimal training } \\
\text { provided, lack of } \\
\text { funding, clients having } \\
\text { concerns about } \\
\text { confidentiality and } \\
\text { having the interpreter's } \\
\text { beliefs and values being } \\
\text { imposed on them. }\end{array}$ \\
\hline
\end{tabular}




\begin{tabular}{|c|c|}
\hline $\begin{array}{l}\text { Van der Boor \& White } \\
\text { (2019) }\end{array}$ & $\begin{array}{l}\text { Barriers to Accessing Compiled } 23 \text { studies } \\
\text { and Negotiating to be analyzed. } \\
\text { Mental Health } \\
\text { Services in Asylum } \\
\text { Seeking and Refugee } \\
\text { Populations: The } \\
\text { Application of the } \\
\text { Candidacy } \\
\text { Framework }\end{array}$ \\
\hline
\end{tabular}

Costa \& Dewaele The Talking Cure - 182

182

clients (2018)

\section{Building the Core Skills and the Confidence of Counsellors and Psychotherapists to Work Effectively with Multilingual Patients Through Training and Supervision} Catherine O'Donnell, "language problem": ALison Phipps, Ima Jackson \& Niamh Stack (2018) Developing an Understanding of the Intersections of
Teresa Piacentini, Moving Beyond the recruited.

$$
\begin{gathered}
\text { multilingual } \\
\text { were }
\end{gathered}
$$

Counsellors should keeping an open mind when working with multilingual clients. Through this, the counsellors can gain a greater empathic understanding towards clients.

19 participants were Refugees and asylum recruited. Health, Language and Immigration Status in Interpreter-mediated Health Encounters

Anastasia A. Interpreting in the Atabekova, Valentina Context of Refugee V. Stepanova, Natalia Migration: Emerging 114 publications were analyzed assessed.

N. Udina, Olga G. Professional Gorbatenko \& Challenges and Needs Tatyana V. Shoustikova (2017)

Georgiadou (2015) "I was seeing more of her": International Counselling Trainees' Perceived Benefits of Intercultural Clinical Practice seekers had a lack of knowledge on how to access the services from interpreters.
11 trainees recruited.

counselling were

Counselling facing language barriers may need to ask for more clarifications to avoid misunderstandings, 
leading them to be more culturally aware.

Robert Schweitzer, Therapeutic Practice Sierra van Wyk \& Kate Murray (2015) with Refugee Clients:

A Qualitative Therapist Experience
12 mental health workers who had an average of 7.6 experience working with refugee clients.

Language barriers can be frustrating to counsellors and may impact the therapeutic relationship and make the therapeutic process more difficult.

Camille Brisset, Yvan Leanza, Ellen Rosenberg, Bilkis Vissandjee, Laurence J. Kirmayer, Gina Muckle, Spyridoula Xenocostas \& Hugues Laforce (2013)

Georgiadou (2013)
Language Barriers in Mental Health Care: A Survey of Primary Care Practitioners
113 practitioners in Montreal were asked to do a self-report survey.

\begin{abstract}
A majority of practitioners had not been trained to work together with interpreters. Clients would often ask their family members or friends to translate.
\end{abstract}

Counselling trainees find it hard to express themselves, understand the client's speech and would feel anxious and have low selfconfidence.

Glenn Flores, Errors of Medical 57 recordings were The limited English Milagros Abreu, Cara Interpretation and recorded which Pizzo Barone, Richard Their Potential include 20 Bachur \& Hua Lin (2012)

Clinical

Consequences:

Comparison Professional Versus professional

A interpreters, 27 ad

of hoc interpreters and

Ad Hoc Versus No interpreters.

Interpreters

M. Brune, F.J. Eiroa- Intermediated

Orosa, J. Fischer- Communication Ortman, B. Delijaj \& C. Haasen (2011)

Interpreters

Psychotherapy

Traumatized

Refugees
190 psychotherapists, No significant

by where half of them

in had the support from differences were found with or no interpreter with interpreters to help refugees with PTSD.

Marie McKeary \& Barriers to Care: The 14 interviews were The waiting time for 


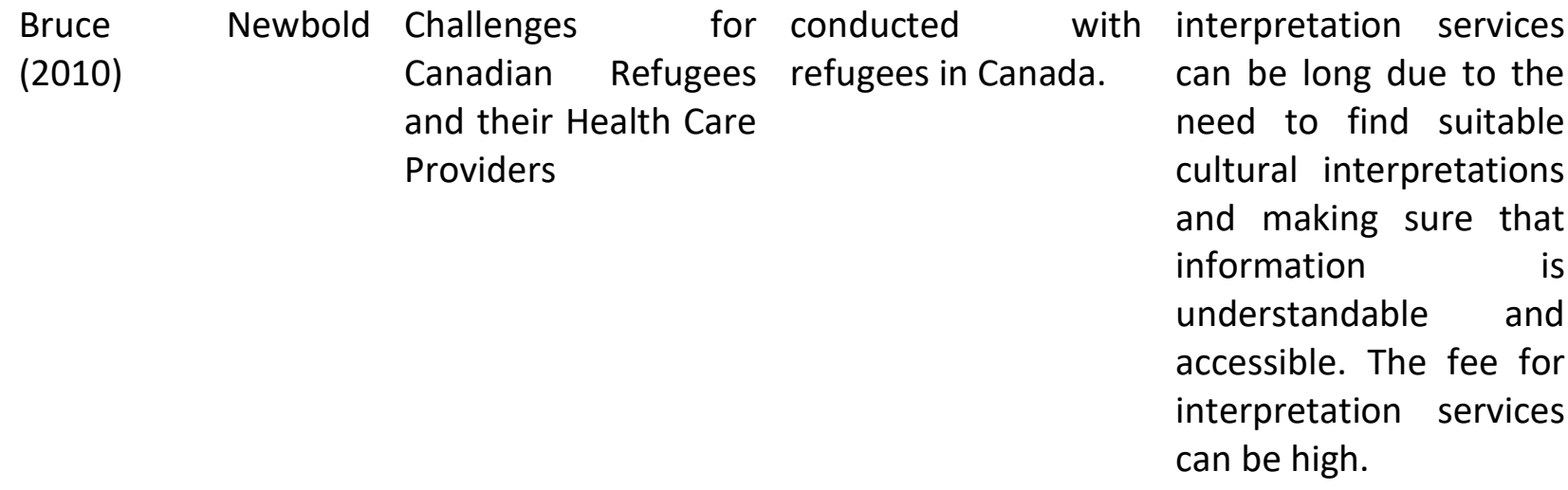

Sharon M. Doherty, How Does It Feel for 157 interpreters were Interpreters were Anna M. Maclntyre \& You? The Emotional recruited. Tara Wyne (2010) Impact and Specific emotionally affected as they find it hard to put clients out of their minds, and may bring it to their personal life. The range of emotions such as helplessness, anger, sadness, hopelessness in a counselling session can lead them to have difficulty moving on to the next client.

\section{Discussion}

There were a lot of impacts that counsellors and refugees faced in a counselling session due to the language barriers. The journal articles that will be used in this systematic review can be compiled into four main impacts, which were: A lack of readiness from both sides, changes in emotional aspect, difficulty understanding each other and the need to rely on interpreters to act as an intermediary.

\section{A Lack of Readiness to Work Together Counsellors}

According to Salami et al (2019), language barriers were considered as one of the more wellknown reasons for people not accessing mental health care services. Usually, refugees who do not know the language of the country would have insufficient knowledge that such services were available and they would have a hard time reaching out. However, one can also say that counsellors would also often have reservations in working with refugees, especially due to the language barriers. These can affect their readiness to work with refugees. According to Schelechter et al (2020), the findings showed that there was a negative correlation between the perceived language barriers and readiness to work with refugees. This is due to the reasons that counsellors display self-doubt, low openness to experiences and high political interest which would prevent them from working readily with refugee clients (Schelechter et al., 2020). Nevertheless, having former experiences in a counselling setting would be of great help to increase readiness (Schelechter et al., 2020). Those who 
were uncomfortable working with interpreters were also reported to be less ready to work with refugees (Schelechter et al., 2020).

\section{Refugee Clients}

On the other hand, refugee clients were also hesitant about working with counsellors. As mentioned in van der Boor and White (2019), the distrust towards health services was high. This is supported by (Salami et al., 2019). Research from Salami et al (2019) found that clients believed mental illness to be a westernized concept that was conspired by healthcare professionals. Most of the clients think that mental illnesses are a crisis of faith, own weaknesses, or being invaded by evil spirits and would only seek help from loved ones or religious figures (Salami et al., 2019). Most of them do not recognize the symptoms of mental illnesses (Salami et al., 2019). Those that do realize they need professional help found that their lack of language fluency skills in the country had impeded their progress to recovery. One would need to wait aimlessly and patiently for an interpreter to be available (Salami et al., 2019). As mentioned in McKeary and Newbold (2010), the waiting time for clinical appointments with non-native English speaking clients will be longer due to the need for an interpreter. Furthermore, the long waiting time was also to make sure that information given out will be understandable and accessible (McKeary \& Newbold, 2010). Even when one had an interest in learning the language, they faced a lack of opportunities to learn and exercise it (Salami et al., 2019).

\section{Emotional Aspect}

Language barriers can also have an emotional impact on counsellors and refugee clients. It can be hard to build a relationship with someone that speaks different languages. According to Rip et al (2020), refugee children may have a hard time opening up to social workers and carers as they do not feel kinship due to language barriers.

Additionally, according to Georgiadou (2013), due to language barriers, it can impact counselling trainees' self-confidence and generate anxiety. This is because they could not speak fluently as it restricts their ability to articulate (Georgiadou, 2013). One such participant in Georgiadou (2013) mentioned that whenever she makes a linguistic mistake, her anxiety will come and engulf her. Due to this, it had an impact on a counsellor's self-perceived competence and became an obstacle for working with refugee clients (Georgiadou, 2013).

The fear of not being good enough can be challenging. When working with refugee clients, it can be difficult to know what they are saying. Therefore, most of the time counsellors would need to voice out their failure to understand what their clients were saying and would need to ask for further clarifications (Georgiadou, 2013). This may cause them to have increased anxiety, coming from a fear of being facilitative towards clients (Georgiadou, 2013). In some cases, it may increase the fear of being rejected and be not up to the 'standards' (Georgiadou, 2013).

However, once the counselling trainees were familiar with the client's culture, understood their own anxiety and confidence, their self-confidence increased and the fear of being inadequate or rejected decreased (Georgiadou, 2013). While language barriers were indeed hard to overcome, they can also be due to unfamiliarity with the subtle cues and meanings of words embedded in their culture. 


\section{Difficulty Understanding Each Other Counsellors}

Even when both counsellors and refugees are willing to work together, they may have a hard time understanding each other. It can prove to be difficult for counsellors as they need to struggle to understand the refugees' backgrounds, unique perspectives and other cultural differences (Schweitzer et al., 2015). This can be especially frustrating and a huge challenge for counsellors (Schweitzer et al., 2015). Other problems are the difficulty to articulate selfexpression and understand the client's speech (Atabekova et al., 2017; Georgiadou, 2013). Therefore, it can be hard to express themselves well due to language barriers (Georgiadou, 2013).

According to Costa and Dewaele (2018), counsellors would often ignore the fact that multilinguals might not encode emotions and experience their worlds differently. Many refugees may have thick and foreign accents that can be difficult to understand (Georgiadou, 2013). Another concern would be that counsellors would be unfamiliar with the subtle meanings of words that can be embedded in a client's culture (Atabekova et al., 2017; Georgiadou, 2013).

Of course, there is an upside to all of these. According to Barreto (2013), his findings suggested that counsellors in a foreign culture and language may listen more attentively, not take things for granted, exhibit more genuine curiosity, respect the differences between them, understand more about life in contrasting contexts and have higher openness. Furthermore, their awareness of self and culture may also be expanded (Barreto, 2013). Their limited vocabulary, accent and inarticulacy would help them to be aware and understand more about their cultural differences (Georgiadou, 2015). For example, to avoid misunderstandings, counsellors would be more attentive and ask for more clarifications (Georgiadou, 2015) to gain a better picture.

\section{Refugee Clients}

Furthermore, it can also bring benefits to the clients involved. As mentioned in Georgiadou (2015), refugee clients would be more culturally aware and thus enhancing their abilities to accept the diversity in their new living place. The clarifications from the counsellors would also make them more in touch with their own experiences and emotions (Georgiadou, 2015). Costa and Dewaele (2018) also mentioned that switching languages in counselling sessions can help the clients to express themselves and their identities more freely and completely. This can be a great way to help clients to self-regulate their proximity towards their own feelings (Costa \& Dewaele, 2018).

\section{The Use of Interpreters}

Sometimes, when working in refugee settings, there were no available counsellors that could speak the same language as refugee clients. With language barriers being tough to overcome, many sought to have interpreters to help translate between the counsellor and clients. This is called a 'therapy in a triangle', which means psychotherapy with help from an interpreter acting as an intermediated communication (Brune et al., 2011). According to Bischoff et al (2003) as cited in Schelechter et al (2020), support from interpreters may be a necessary component in a therapeutic setting. 


\section{Disagreements on Having Interpreters}

One cannot deny that the core of healthcare services is communication (Piacentiti et al., 2019). However, many would argue about the need to have interpreter services. On one hand, having an interpreter may be a less-than-ideal solution (Baxter \& Cheng, 1996 as cited in Brune et al., 2011) compared to having only counsellor and client. According to Brisset, Leanza and Laforest (2013) as cited in Salami et al (2019), having the presence of an interpreter may distract the counsellor and lead to a perceived loss of control in the session. Without a doubt, many counsellors felt uncomfortable working with interpreters, which would lead them to be less ready to work with refugees (Schelechter et al., 2020). The higher the perceived language barriers, the higher the counsellors would be uncomfortable working with interpreters (Schelecter et al., 2020). The uncomfortableness may contribute to reasons such as confidentiality issues and the quality of communication (Kizilhan, 2017 as cited in Schlechter et al., 2020). For example, according to McKeary and Newbold (2010), the fee for interpretation can be high as it was very expensive. Therefore, to make up for it, clients would often resort to having their family members adopt the role of an interpreter when accessing mental health services (Salami et al., 2019). This is called ad hoc interpreters. According to Flores et al (2012), the use of ad hoc interpreters or no interpreters at all will lead to higher misinterpretation compared to professional interpreters. Other problems such as loss of confidentiality and increased burden on family members will also happen (Salami et al., 2019; van der Boor \& White, 2019) and lack of understanding of medical terminology (Salami et al., 2019). As an interpreter, one would need to understand their roles fully in order to be of help in a counselling session. Rapports should also be built with clients by interpreters and allow the clients to understand the confidentiality boundaries within counselling (Salami et al., 2019).

Without a doubt, there are not many interpreters out there that would help out in counselling. Due to the lack of interpreters, it can be hard to find someone that can take up the role and fulfil it properly. According to Brisset et al (2013), although interpreters may seem like a necessity, most of them were provided minimal training. Therefore, clients often voiced their concerns about having their confidentiality broken and having the interpreters' beliefs and values being imposed on them during their conversation with counsellors (Brisset et al., 2013; Boor \& White, 2019). This is because most often than not, the process of evaluating the interpreter-client fit was ignored (Salami et al., 2019). Even though the interpreter and client spoke the same language, they would have a difference in religion, class, political lines and backgrounds which can result in reciprocal distrust and tension (Salami et al., 2019). This is especially true if the interpreter and the client come from the same communities. Due to the nature of their communities being close-knitted, many clients worry about the interpreter jeopardizing their confidentiality and telling it to others in their same community (Salami et al., 2019).

Another concern was the lack of funding to hire full-time positions of interpreters (Brisset et al., 2013). These translational services were rarely available, especially for those who have rare spoken languages and dialects (van der Boor \& White, 2019). Due to these reasons, refugees were scared to reach out due to fear (van der Boor $\&$ White, 2019). The low quality of interpreter services would impede a counselling session, such as decreasing empathetic responses, lower rapport and satisfaction (Costa \& Bewaele, 2018). Backed up by 
Brune et al (2011), one would also expect to have a distortion in transference, complicated group dynamics and cultural incongruences in counselling.

Therefore, without proper training and knowledge, it can lead to a string of problems. Interpreters themselves would experience a decline in their health due to distress. The discussion in the counselling room can be emotionally distressing for interpreters and according to Doherty et al. (2010), 56\% of respondents in their study would find it difficult to remove the thoughts from their minds and $23 \%$ would think about it for extended periods of time. In a counselling session, they would often feel hopeless, anger, sad, guilt and powerless, which would prevent them from moving on to their next job (Doherty et al., 2010). They would also have no outlets for this distress (Doherty et al., 2010). If not careful, it can also be spilt over to their personal life (Doherty et al., 2010). Therefore, some would avoid doing these mental health jobs due to the potential risks (Doherty et al., 2010).

\section{Agreements on Having Interpreters}

On the other hand, there are also people who support interpreter-assisted therapy use. According to Bischoff et al (2003) as cited in Schelechter et al (2020), support from interpreters may be a necessary component in a therapeutic setting. d'Ardenne et al (2007) as cited in Schelechter et al (2020) stated that having interpreters may be beneficial if conducted appropriately. Furthermore, the clients may even feel appreciated by having another presence in the session (Schelechter et al., 2020). A study by Brune et al. (2011) found that the presence or absence of interpreters were just as effective vice versa. Therefore, it can be debated that if counsellors are willing and motivated to work together with interpreters, they can work just as well to help the refugee clients (Brune et al., 2011).

\section{Limitations and Implications}

Without a doubt, there will be a few limitations on our systematic review. One of the limitations may include that the journal articles were screened and only selected for those written in English while other languages were excluded. Most of the articles that we have included in this systematic review were mostly qualitative studies, which involves various opinions of counsellors and refugee clients alike. Therefore, this may lead to bias results due to social desirability and underreporting. Furthermore, due to the limited number of journal articles found, journal articles that involve counselling trainees and general mental health services were also included. While it is also related to the topic of our systematic review, it is viewed in a much broader context compared to just in a counselling context.

Inherently, different countries may face language barriers differently. Due to having individualistic and collectivist cultures, there would be different opinions in having interpreters around and how the counsellors may think and act. Other than that, each country would also have their own rules and regulations regarding confidentiality issues by having guidelines such as from American Psychology Association (APA). Even though most of the countries follow these guidelines, there are still some exceptions that follow other guidelines. Nonetheless, in our systematic reviews, we conclude the journal articles and synthesize them as a whole. 


\section{Conclusion}

One of the most prominent barriers to accessing mental health care was language. Evidently, language plays a huge role in counselling and forms a bridge to connect counsellors and clients. However, as refugees came from different countries all around the world, they would likely have different cultural backgrounds and varying languages. This causes refugee clients and counsellors to have language barriers. Based on the discussion above, we were able to have a better understanding on the impacts of language barriers that counsellors and refugee clients faced in counselling. The impacts analyzed in this paper revealed a lack of readiness from both sides, changes in emotional aspect, difficulty understanding each other and the need to rely on interpreters to act as the intermediaries.

For counsellors, they would have reservations about working with refugees due to language barriers. This may include having interpreters and fewer experiences on this matter. For clients, most of them worry about confidentiality issues. The cultural background that discourages mental health services also played a huge role.

As discussed, language barriers can also have an emotional impact on counsellors and refugee clients. Georgiadou (2013) found that self-confidence and anxiety would have an impact on counselling trainees. Due to language barriers, it can be hard to understand each other. It may be frustrating for the counsellors (Schweitzer et al., 2015) as they found it hard to articulate self-expression, understand the client's speech and worry about the unfamiliar subtle cues and meanings from their cultures (Atabekova et al., 2017; Georgiadou, 2013). However, these experiences can also make the counsellors and clients be more aware of their own inabilities and accept the diversity while being open-minded.

Ultimately, there were different opinions on using interpreters in a counselling session. On one hand, some rejected this idea as having the presence of an interpreter may be distracting to the counsellor and lead to a perceived loss of control in the session (Brisset, et al., 2013 as cited in Salami et al., 2019). Some counsellors would also feel uncomfortable because of confidentiality issues, quality of communication (Kizilhan, 2017 as cited in Schlechter et al, 2020), a lack of understanding of medical terminology (Salami et al., 2019), and minimal qualifications of interpreters (Brisset et al., 2013). This is also worrying for refugee clients as they were scared of having their confidentiality broken, and having the interpreters' beliefs and values being imposed on them during their conversation with counsellors (Brisset et al., 2013; van der Boor \& White, 2019). On the other hand, some suggested that it may be beneficial (Brune et al., 2011; Schelechter et al., 2020) if counsellors were willing and motivated to work alongside interpreters (Brune et al., 2011).

Some suggestions to improve the counsellor's readiness may be to prepare competence training and workshops to help counsellors feel more comfortable working with interpreters (Schouler-Ocak et al., 2015 as cited in Schelechter et al., 2020). Another would be to hire more professional interpreters that had training in these areas. As counsellors, one must be open-minded and tolerate ambiguity when working with clients that are multilingual (Costa et al., 2018). With open-mindedness, comes empathic understanding. Empathy can greatly improve effectiveness in a counselling session (The Value of Empathy in Counselling, 2019) and build rapport between counsellor and client. Therefore, counsellors should be sensitive and open to linguistic differences. With this in mind, the refugees may feel more comfortable and be more open to sharing their experiences. Other than this, to prevent language barriers, talks and briefings should be given to refugees. As mentioned by Salami et al (2019), refugees had a hard time recognizing the symptoms of mental illnesses due to their 
lack of knowledge. Therefore, one would definitely need education and awareness in mental health so that refugees would be able to seek help if needed. All in all, we hope that this study will be able to push future research endeavors to help counsellors and refugee clients.

\section{Funding}

This research received no financial support from any funding agency, commercial, or not-forprofit

sectors for the research, authorship, and/or publication of this article.

\section{Declaration of Conflicting Interests}

The author(s) declared no potential conflicts of interest with respect to the research, authorship,

and/or publication of this article.

\section{Originality of This Article}

The author(s) acknowledged that this is the original work and has not been submitted to nor published anywhere else.

\section{References}

Aspinall, P., \& Watters, C. (2010). Refugees and asylum seekers: A review from an equality and human rights perspective. Equality and Human Rights Commission Research report 52, University of Kent.

Atabekova, A. A., Stepanova, V. V., Udina, N. N., Gorbatenko, O. G., \& Shoustikova, T. V. (2017). Interpreting in the context of refugee migration: Emerging professional challenges and needs. XLinguae, 10(4), 184-195. https://doi.org/10.18355/xl.2017.10.04.15

Beiser, M., \& Hou, F. (2017). Predictors of positive mental health among refugees: Results from Canada's General Social Survey. Transcultural Psychiatry, 54(5-6), 675-695. https://doi.org/10.1177/1363461517724985

Blackmore, R., Boyle, J. A., Fazel, M., Ranasinha, S., Gray, K. M., Fitzgerald, G., ... \& GibsonHelm, M. (2020). The prevalence of mental illness in refugees and asylum seekers: A systematic review and meta-analysis. PLoS medicine, 17(9), e1003337.

Brisset, C., Leanza, Y., Rosenberg, E., Vissandjée, B., Kirmayer, L. J., Muckle, G., Xenocostas, S., \& Laforce, H. (2013). Language barriers in mental health care: A survey of primary care practitioners. Journal of Immigrant and Minority Health, 16(6), 1238-1246. https://doi.org/10.1007/s10903-013-9971-9

Brune, M., Eiroá-Orosa, F., Fischer-Ortman, J., Delijaj, B., \& Haasen, C. (2011). Intermediated communication by interpreters in psychotherapy with traumatized refugees. International Journal of Culture and Mental Health, 4(2), 144-151. https://doi.org/10.1080/17542863.2010.537821

Costa, B., \& Dewaele, J. (2018). The talking cure-building the core skills and the confidence of counsellors and psychotherapists to work effectively with multilingual patients through training and supervision. Counselling and Psychotherapy Research, 19(3), 231-240. https://doi.org/10.1002/capr.12187

Crepet, A., Rita, F., Reid, A., Van den Boogaard, W., Deiana, P., Quaranta, G., ... Di Carlo, S. (2017). Mental health and trauma in asylum seekers landing in Sicily in 2015: a 
descriptive study of neglected invisible wounds. Conflict and Health, 11(1). https://doi.org/10.1186/s13031-017-0103-3

Doherty, S., Maclntyre, A., \& Wyne, T. (2010). How does it feel for you? The emotional impact and specific challenges of mental health interpreting. Mental Health Review Journal, 15(3), 31-44. https://doi.org/10.5042/mhrj.2010.0657

Eaton, V., Ward, C., Womack, J., \& Taylor, A. (2011). Mental Health and Wellbeing in Leeds: An Assessment of Need in the Adult Population. NHS Leeds.

Flores, G., Abreu, M., Barone, C. P., Bachur, R., \& Lin, H. (2012). Errors of medical interpretation and their potential clinical consequences: A comparison of professional versus ad hoc versus no interpreters. Annals of Emergency Medicine, 60(5), 545-553. https://doi.org/10.1016/j.annemergmed.2012.01.025

Frounfelker, R. L., Mishra, T., Dhesi, S., Gautam, B., Adhikari, N., \& Betancourt, T. S. (2020). "We are all under the same roof": Coping and meaning-making among older Bhutanese with a refugee life experience. Social Science \& Medicine, 264, 113311. https://doi.org/10.1016/j.socscimed.2020.113311

Georgiadou, L. (2013). 'My language thing ... is like a big shadow always behind me': International counselling trainees' challenges in beginning clinical practice. Counselling and Psychotherapy Research, 14(1), 10-18. https://doi.org/10.1080/14733145.2013.770896

Georgiadou, L. (2015). 'I was seeing more of her': International counselling trainees' perceived benefits of intercultural clinical practice. British Journal of Guidance \& Counselling, 43(5), 584-597. https://doi.org/10.1080/03069885.2014.996735

McKeary, M., \& Newbold, B. (2010). Barriers to care: The challenges for Canadian refugees and their health care providers. Journal of Refugee Studies, 23(4), 523-545. https://doi.org/10.1093/jrs/feq038

Moher, D. (2009). Preferred reporting items for systematic reviews and meta-analyses: The PRISMA statement. Annals of Internal Medicine, 151(4), 264. https://doi.org/10.7326/0003-4819-151-4-200908180-00135

Piacentini, T., O'Donnell, C., Phipps, A., Jackson, I., \& Stack, N. (2018). Moving beyond the 'language problem': Developing an understanding of the intersections of health, language and immigration status in interpreter-mediated health encounters. Language and Intercultural Communication, 19(3), 256-271. https://doi.org/10.1080/14708477.2018.1486409

Rip, J., Zijlstra, E., Post, W., Kalverboer, M., \& Knorth, E. J. (2020). 'It can never be as perfect as home': An explorative study into the fostering experiences of unaccompanied refugee children, their foster carers and social workers. Children and Youth Services Review, 112, 104924. https://doi.org/10.1016/j.childyouth.2020.104924

Sagbakken, M., Bregård, I. M., \& Varvin, S. (2020). The past, the present, and the future: A qualitative study exploring how refugees' experience of time influences their mental health and well-being. Frontiers in Sociology, 5. https://doi.org/10.3389/fsoc.2020.00046

Salami, B., Salma, J., \& Hegadoren, K. (2019). Access and utilization of mental health services for immigrants and refugees: Perspectives of immigrant service providers. International Journal of Mental Health Nursing, 28(1), 152-161. https://doi.org/10.1111/inm.12512 
Schlechter, P., Hellmann, J. H., Wingbermühle, P., \& Morina, N. (2020). Which psychological characteristics influence therapists' readiness to work with refugees? Clinical Psychology \& Psychotherapy, 28(2), 334-344. https://doi.org/10.1002/cpp.2508

Schweitzer, R., Van Wyk, S., \& Murray, K. (2015). Therapeutic practice with refugee clients: A qualitative study of therapist experience. Counselling and Psychotherapy Research, 15(2), 109-118. https://doi.org/10.1002/capr.12018

Shaw, S. A., Rodgers, G., Poulin, P., Minor, O., \& Ashley, A. (2020). Safety among newly resettled refugees in the USA. Journal of International Migration and Integration, 118. https://doi.org/10.1007/s12134-020-00786-x.

Silove, D., Ventevogel, P., \& Rees, S. (2017). The contemporary refugee crisis: An overview of mental health challenges. World Psychiatry, 16(2), 130-139. https://doi.org/10.1002/wps.20438

United Nations High Commissioner for Refugees. (2021). Figures at a Glance in Malaysia. UNHCR. https://www.unhcr.org/en-my/figures-at-a-glance-in-malaysia.html

The value of empathy in counselling. (2019, September 30). Counselling Connection. https://www.counsellingconnection.com/index.php/2010/04/27/the-value-ofempathy/

Van der Boor, C. F., \& White, R. (2019). Barriers to accessing and negotiating mental health services in asylum seeking and refugee populations: The application of the candidacy framework. Journal of Immigrant and Minority Health, 22(1), 156-174. https://doi.org/10.1007/s10903-019-00929-y

Ziersch, A., Due, C., \& Walsh, M. (2020). Discrimination: a health hazard for people from refugee and asylum-seeking backgrounds resettled in Australia. BMC Public Health, 20(1). https://doi.org/10.1186/s12889-019-8068-3 